\title{
TEORIA POLÍTICA E PESQUISA SOCIAL
}

Rúrion Melo

é professor do Departamento de Ciência Política da Universidade de São Paulo e pesquisador do Centro Brasileiro de Análise e Planejamento (Cebrap). São Paulo, SP. Brasil.

E-mail:<rurion@usp.br>

http://dx.doi.org/10.1590/0102-211230/102

Apesar da rica e considerável diversidade, tornou-se comum identificar a atividade da teoria política como reflexão conceitual muito específica, voltada à história da própria teoria, a seus autores destacados e reconhecidos na tradição política ou a certas concepções abstratas sobre valores, ideais e aspirações normativas. A organização institucional e disciplinar da ciência política tem em grande medida replicado essa identificação, distinguindo parâmetros mais gerais em que fosse possível separar a investigação sobre processos históricos e empíricos da vida política, de um lado, de formulações teóricas, de outro. Ideal e real, normativo e positivo, imanente e transcendente são algumas dicotomias pressupostas quando se procura estabelecer o lugar mais abstrato da teoria política. Sobretudo atualmente, as teorias políticas normativas parecem corroborar (nem sempre de maneira autodeclarada) tal identificação atrelada a uma abordagem "ideal", como que separada da política "real".

Diante de tal quadro, a ciência política se vê repartida por dois modos aparentemente incompatíveis de concepção: um mais teórico (e, principalmente, mais normativo) e 
outro empírico (pautado em certos processos, atores e instituições quantitativamente mensuráveis). Recai sobre a teoria política nessa repartição a desconfiança com o meramente abstrato e especulativo como algo que em alguns casos pode contribuir com o conhecimento sobre a realidade política (neste caso, à teoria caberia função meramente instrumental para estudos empíricos), mas que em si não resguardaria potencial explicativo adequado para pretender clarificar a realidade. Ou então a teoria procura circunscrever seu campo próprio de estudo precisamente pela dimensão "não empírica" em que naturalmente se vê confinada, reforçando, como consequência, as mencionadas dicotomias.

Este artigo parte do juízo de que é contraproducente pensar teoria política com base na dicotomia real versus ideal. Toda boa investigação empírica da realidade política lança mão de referências teóricas mais ou menos explicitadas, assim como é intenção da teoria contribuir com a 212 investigação a respeito da vida política. A dificuldade, claro, é compreender de que maneira as diferentes teorias políticas alcançam este propósito geral. Pretendo tratar aqui da forma específica em que a teoria política não seja considerada em oposição ou em concorrência com a dimensão mais empírica da ciência política. Em outros termos, a teoria política deve refletir sobre seu próprio procedimento de fundamentação, assumindo papel complementar e reciprocamente constitutivo com a pesquisa social. Dessa forma, têm a ganhar não apenas estudos empíricos sobre a sociedade (com compreensão conceitual e categorialmente plural, rigorosa e precisa), mas, antes de tudo, a própria teoria, na medida em que testa e renova a fundamentação de seus conceitos e categorias tendo em vista experiências, conflitos e processos diante dos quais a cada vez se vê confrontada.

Mesmo reconstruções abrangentes e plurais a respeito da teoria política muitas vezes concentram sua atenção na análise dos diferentes pressupostos de fundamentação das 
diversas escolas e tradições, deixando de sublinhar, porém, os momentos em que a constituição categorial de algumas escolas e tradições requer trabalho conjunto com a pesquisa social. A meu ver, a teoria política é fundamental para as ciências sociais em geral, uma vez que faz parte do esforço interdisciplinar de produzir diagnóstico adequado sobre os conflitos políticos de nosso tempo. Conflitos a respeito dos limites da democracia representativa, do déficit de legitimação do Estado de direito, das formas de participação política e da cidadania, das reivindicações por direitos e por justiça, das lutas por reconhecimento, da compreensão da cultura política e das disputas na esfera pública - em todos estes e em outros casos não faz mais sentido separar pesquisa empírica, levantamento e análise de dados, tratamento qualitativo e desenhos institucionais da reflexão a respeito das concepções ideais ou normativas em disputa e sempre pressupostas nas práticas sociais.

Para elaborar a questão sobre a relação entre teoria política e pesquisa social, organizei este artigo em duas partes. Na primeira seção, pretendo acompanhar a exposição já reconhecida de Andrew Vincent (2004) a respeito do vasto campo da teoria política, procurando destacar sua análise sobre a teoria crítica elaborada por Jürgen Habermas. Meu intuito consiste em mostrar que, a despeito da abrangência e complexidade das escolas, tradições e atualizações contemporâneas da teoria política apresentadas em seu livro, Vincent deixa de destacar a peculiaridade do método reconstrutivo da teoria política habermasiana. A peculiaridade desse método consiste no fato de que a teoria política reconstrutiva pretende permanecer aberta aos contextos sociais por intermédio de pesquisas interdisciplinares. Meu intuito nessa seção consiste não apenas em compreender os pressupostos da "reconstrução", mas também utilizar o exemplo habermasiano para sublinhar dificuldades e limites do método reconstrutivo na teoria política. 
Por fim, na segunda seção, gostaria de reforçar uma forma de pensar a fundamentação de conceitos da teoria política de tal modo que se mantenha uma relação de complementaridade entre aspectos normativos e pesquisa social. De um lado, a teoria política permite à pesquisa social organizar conceitualmente certos processos empíricos. De outro, os próprios conceitos teóricos são reconstituídos e renovados em seu sentido pela pesquisa social pressuposta. O importante é evitar, primeiro, que a teoria política não possa contribuir com a compreensão do tempo presente uma vez que, de acordo com a exposição aqui sugerida, seus conceitos devem poder ser fundamentados nas relações históricas e políticas que pretende iluminar. Em segundo lugar, evitaríamos que todo elemento empírico recebesse tão somente o estatuto de mero exemplo de conceitos já teórica e previamente fundamentados. Pelo contrário, é possível entender que a pesquisa social contribui de maneira 214 imanente na gênese dos próprios conceitos da teoria política. Termino exemplificando como poderia ocorrer uma tal contribuição a partir de pesquisas atuais sobre "lutas por reconhecimento", que têm sido desenvolvidas e renovadas com diferentes abordagens empíricas.

\section{Teoria política reconstrutiva: potenciais e limites}

O livro The Nature of Political Theory, de Andrew Vincent (2004), já é referência nos estudos sobre teoria política. Correntes, conceitos e autores centrais do pensamento político contemporâneo são sistematicamente apresentados e organizados de maneira abrangente. Para marcar a abrangência e a pluralidade, o autor questiona a divisão de fundo tradicionalmente aceita entre aqueles que organizam correntes do pensamento político entre cinco "fundações fortes" da teoria política: clássica, institucional, histórica, empírica e ideológica (Vincent, 2004, pp. 19-80). De acordo com a tese geral defendida em seu livro, Vincent 
precisa mostrar que a divisão das cinco fundações fortes não é totalmente equivocada, mas acabaria sendo rigidamente determinada. Consequentemente, precisaríamos flexibilizá-la (e, no limite, superá-la) caso quiséssemos abarcar outras possíveis "fundações" da teoria política contemporânea por serem mais diversamente constituídas em várias correntes e subcorrentes. Assim, a apresentação das diferentes correntes da teoria política permite que esses cinco aspectos que caracterizam as "fundações fortes" possam ser relativizados e atualizados na gama mais plural e abrangente de fundações renovadas (Vincent, 2004, pp. 7-8).

Vincent também está insatisfeito com distinções simplificadoras da teoria política. As fundações renovadas não possuem apenas fundamentos teóricos muito diversos, elas principalmente evitam ou negam dicotomias pressupostas nas divisões tradicionais (teoria política ideal versus real, transcendente versus imanente, normativa versus empírica etc.). E esta é razão de o autor lançar mão de uma interpretação mais complexa e necessariamente mais inclusiva de formas de fundamentar a teoria política. $\mathrm{O}$ empreendimento de Vincent é digno de reconhecimento, sua argumentação em prol de cruzamentos entre elementos normativos e imanentes, entre idealizações e práticas políticas é rigorosa e bem demonstrada por dentro das mais diversas correntes. Eu gostaria de voltar minha atenção tão somente para o modo como Vincent incorpora em sua complexa apresentação das diversas correntes uma tradição de pensamento em especial, a "teoria crítica", principalmente o papel de destaque que atribui à teoria política elaborada por Jürgen Habermas.

Evidentemente, Vincent não afirma que Habermas empregou conceitos da teoria política de maneira meramente especulativa. Reconhece, por exemplo, que a história da sociedade civil burguesa (no caso dos estudos de Habermas a respeito da mudança estrutural da esfera pública) ou os novos movimentos sociais (na qualidade de 
pressupostos da reflexão habermasiana sobre o direito e a democracia) permanecem vinculados aos conceitos desenvolvidos por Habermas, já que o filósofo elabora uma reflexão sobre a política a partir de uma teoria mais abrangente da sociedade. É como se estivesse sempre preocupado em olhar tanto para a história e para certos processos sociológicos da realidade democrática, de um lado, quanto para as referências da teoria política propriamente dita, de outro.

No que concerne ao modo de fundamentação desta teoria, Vincent entende que está acima de tudo baseada em "fundação dialógica", em uma teoria do discurso e da ação comunicativa (Vincent, 2004, p. 271). O decisivo, portanto, consiste nessa "lente dialógica" pela qual Habermas analisa a vida política e social. Contudo, a investigação relativa à sociedade e à história, os diagnósticos de tempo a respeito do capitalismo, do direito e dos movimentos sociais, bem como a maneira com que tais diagnósticos se encontram 216 fundados sobre um conjunto de pesquisas sociais que não são tratadas como traços da "fundação" dessa teoria política. O autor limita a reconstrução habermasiana a um "pensamento reconstrutivo", "abstrato", voltado ao desenvolvimento da história das teorias do ponto de vista de uma "lógica comunicativa interna" pressuposta (Vincent, 2004, p. 280) ou à reconstrução mais direta de elementos racionais e normativos inscritos nas ações comunicativas e nas práticas discursivas (Vincent, 2004, p. 284). Mais especificamente, o autor parece desconsiderar que o método reconstrutivo precisa incorporar recursos mais interdisciplinares, principalmente aqueles ligados à pesquisa social que constituem em conjunto a fundamentação de conceitos políticos normativos (Bernstein, 1976; McCarthy, 1981; Nobre e Repa, 2012).

Dessa forma Vincent deixaria de lado o que seria decisivo para seu próprio propósito, já que manteria ainda de maneira externa a relação dos conceitos e categorias da 
teoria com abordagens mais realistas ou sociais que deveriam pressupor. Porém, o mais específico da abordagem da teoria crítica em geral, e de Habermas em especial, consiste em compreendermos o vínculo dessas duas dimensões (a social e a teórica, por assim dizer) de tal maneira que possam se constituir reciprocamente - não como teoria política cujos conceitos serão empregados apenas posteriormente a realidades sociais que serão investigadas, ou como investigação empírica que nada modificará na constituição dos conceitos utilizados pela teoria. O conceito deve nos permitir identificar certas aspirações normativas no conjunto de processos e práticas sociais, de um lado, mas deve também poder ser constituído e, se necessário, torcido e renovado pela singularidade da complexidade dos processos sociais, das disputas e experiências que nos ajuda a compreender.

Isso decorreria, primeiro, do fato de que, ao tratar da abordagem histórica da teoria política (voltada a discursos, crenças e materiais culturais que possam ajudar à compreensão do contexto histórico em que foram produzidas as teorias políticas de referência), da teoria política institucional (com destaque para estudos a respeito do Estado) ou da teoria política empírica (voltada, em abordagens variadas, ao comportamento político mais positivo e realista, em contraposição às aspirações normativas ou ideológicas), Vincent acaba destacando tão somente uma distinção de objetos e modos de investigação, mantendo a contragosto a dicotomia de fundo entre concepções normativas, de um lado, e aquelas mais empíricas, de outro. Assim, debruça-se no método reconstrutivo como se fosse uma ferramenta limitada à reconstrução de aspectos normativos da evolução histórica e social.

Uma definição central de reconstrução se aplica abertamente a tais aspectos normativos pressupostos por crítica imanente, como o próprio Vincent reconhece. Falta, contudo, entender que Habermas emprega a teoria política 
do ponto de vista de uma metodologia reconstrutiva cujo propósito é demonstrar a gênese das aspirações normativas segundo diagnósticos sociais abrangentes. ${ }^{1}$ Por que isso teria sido importante? Porque a teoria política reconstrutiva tem uma especificidade que ficou de fora na organização sugerida por Vincent. Do ponto de vista da fundamentação e da produção das próprias categorias, pretende não se colocar de maneira externa aos processos e fenômenos políticos que pretende esclarecer, pois os conceitos não podem ser apenas aplicados à realidade dada. ${ }^{2}$ Andrew deixou de mostrar que a história de desenvolvimento da teoria crítica se deu juntamente com aquilo que Max Horkheimer (2009) concebeu como o projeto do materialismo interdisciplinar, ou seja, um arranjo disciplinar entre várias áreas do conhecimento (política, direito, psicanálise, filosofia, economia, sociologia etc.) que tinha por finalidade produzir um diagnóstico crítico do tempo presente, arranjo que se efetivou no Instituto de Pesquisa Social de Frankfurt durante muitos anos (Jay, 2008). Nesse mesmo quadro, a teoria política reconstrutiva é fundamentada não por uma concorrência, mas sim por uma complementaridade com pesquisa socais. Isso é diferente, portanto, de entender a teoria política de Habermas como composta de elementos às vezes históricos, outras vezes empíricos, mas na sua maioria ideológicos e normativos

\footnotetext{
1 "Reconstruir é o modo específico por meio do qual se podem ancorar na realidade das sociedades capitalistas avançadas os potenciais emancipatórios, os quais demonstrariam, simultaneamente, a possibilidade real do conteúdo normativo próprio dos critérios que orientam a crítica da sociedade e das teorias sociais tradicionais" (Nobre e Repa, 2012, p. 18).

2 Seja para dizer, por exemplo, que determinado conceito de liberdade ou de justiça, previamente fundamentado, teria lugar na consideração de determinado processo político (sem que esse mesmo processo tivesse contribuído para atualizar os conceitos aplicados), seja para dizer, ao contrário, que conceitos bem fundamentados de liberdade ou justiça não foram empiricamente identificados e, nesse segundo caso, serviriam apenas para que a teoria pudesse mostrar sua ausência nas realidades empíricas. Aqui, no segundo exemplo, a teoria política seria uma espécie de "teoria política da ausência".
} 
(por causa da aspiração crítica da teoria) que conseguem, apenas em certa medida, compor-se mutuamente. ${ }^{3}$

Por fim, isso permitiria também a Vincent ressaltar dificuldades imanentes a esta abordagem reconstrutiva de teoria política. Ainda que o projeto de reconstrução de Habermas seja um bom exemplo para pensar a constituição entre teoria política e pesquisa social, por outro lado também nos ensina sobre algumas dificuldades. Para tanto, é preciso entender, primeiramente, os pressupostos da noção metodológica de reconstrução (basicamente, dizendo respeito à exigência de que os conceitos critico-normativos tenham enraizamento social), e, em segundo lugar, ao menos duas maneiras em que a reconstrução foi empregada na obra de Habermas: uma vinculada à pesquisa social e outra mais independente.

Vincent está correto quando identifica que Habermas (2004, p. 4) procura desenvolver uma "teoria política imanente". Na sua interpretação, no entanto, Habermas procurou a imanência em um quadro excessivamente "neokantiano" (o racional e o normativo como traço transcendental de toda ação comunicativa), o que levou a uma tensão constitutiva com a fundamentação imanente pretendida. Essa interpretação reduz a ideia geral da crítica imanente como ponto de partida da teoria social e política. Segundo o pressuposto fundamental da reconstrução, toda categoria

\footnotetext{
${ }^{3}$ Reforça-se assim o caráter mediador da pesquisa social, a partir do qual outras categorias são reconstruídas. É insuficiente, portanto, dizer que determinado conflito em torno de práticas democráticas está ancorado no conceito teórico de comunidade política, por exemplo. É o conceito de comunidade política enquanto tal que precisaria ser reconstruído com base em pesquisas sociais e empíricas, contribuindo na produção de uma categoria normalmente multifacetada e inclusive ambígua. Assim, o ancoramento social de um conceito (liberdade, autonomia, igualdade etc.) não consiste em derivar simplesmente de outro (comunidade, sociedade, cidadania etc.). Por esta razão, a pesquisa social é constitutiva do conceito da teoria, permitindo inclusive, como defendo aqui, enriquecer a fundamentação teórica, não apenas servir de exemplo concreto de conceitos já constituídos. Em artigo recente, Habermas (2008) tratou desse aspecto mediador para estudos atuais sobre a democracia e a esfera pública.
} 
teórica deve estar vinculada tanto a um "contexto de surgimento" quanto a um "contexto de aplicação" (Habermas, 2013, pp. 25-26). A reconstrução implica assim conexão ou ancoramento em contextos históricos e sociais, os quais assumem papel constitutivo na produção das categorias que a teoria está desenvolvendo. Conceitos políticos não devem ser anistóricos ou metafisicamente fundamentados de uma vez por todas, já que são parte de um diagnóstico da sociedade e dos conflitos políticos renovados a cada instante. $\mathrm{Na}$ mesma medida em que a teoria diagnostica a sociedade, também ilumina de onde a teoria poderá reconstruir seus conceitos centrais, mas nunca definitivos.

Durante a década de 1970, Habermas procurou efetivar tais exigências de fundamentação teórica com base em um grande e pretensioso projeto de pesquisa interdisciplinar denominado "ciências sociais reconstrutivas". Tratava-se de manter a ideia de produzir diagnósticos críticos sobre a 220 sociedade, o capitalismo, o direito, o Estado e a formação da personalidade, mediante reorganização interdisciplinar das ciências sociais e suas áreas de pesquisa empírica. Nesse projeto amplo, a teoria política teve papel decisivo porque permitiu reconstruir conflitos em torno da justiça e da legitimidade, que contavam com estruturas simbólicas profundas e que sistematizavam regras sociais em determinados momentos históricos (Habermas, 2016).

No entanto, a partir de 1981 o projeto das "ciências reconstrutivas" começa a ser complementado com a "reconstrução da história da teoria", o outro sentido de reconstrução em sua obra. ${ }^{4}$ De posse de uma teoria do discurso, Habermas pode então reconstruir outras teorias sociais e políticas como se fossem, elas mesmas, teorias reconstrutivas. Isso vale diretamente para a interpretação que o filósofo fez

\footnotetext{
4 Refiro-me aqui a seu mais importante livro (Teoria da ação comunicativa), de 1981, que marca na verdade um distanciamento com relação às pesquisas empíricas. Sobre este outro sentido de reconstrução, cf. Nobre e Repa (2012).
} 
de teóricos sociais (Karl Marx, Max Weber, Émile Durkheim, Talcott Parsons), mas também para teóricos políticos modernos (Rousseau, Kant) e contemporâneos (Robert Dahl, John Rawls, Seyla Benhabib, Joshua Cohen, Nancy Fraser etc.). Nesse caso a reconstrução se dirige não apenas às teorias elaboradas, mas também à compreensão de determinadas práticas políticas pressupostas na formação da vontade e da deliberação política. A reconstrução que Habermas passa a fazer do direito e da democracia pressupõe dimensões intersubjetivas de aceitabilidade racional e de práticas discursivas com fortes e variadas pretensões normativas, mas também abarca a reconstrução de negociações, barganhas, ações estratégicas e aspectos sistêmicos da realidade política e da circulação do poder na esfera pública (Habermas, 1994; Melo e Silva, 2012).

Habermas sofreu críticas de variadas ordens em relação à preocupação central de reconstruir as condições procedimentais para a compreensão crítica da democracia. Dentre tais críticas, algumas sublinham a relação entre a teoria habermasiana da democracia deliberativa e do direito procedimental com as pesquisas empíricas que poderiam ter corroborado as teses normativas defendidas. Afinal, o modelo procedimental de democracia radical estava sendo tão somente deduzido de uma teoria discursiva do direito e da democracia ou contava de fato com diagnósticos sobre os conflitos políticos e jurídicos amplamente apoiados em pesquisas empíricas? Estaria então Habermas correndo o risco de derivar sua teoria política reconstrutiva diretamente da formulação normativa, sem a exigida mediação com a pesquisa social? (Voirol, 2012).

De acordo com leitura já apresentada em outras ocasiões (Melo e Silva, 2012; Melo, 2015), a teoria política de Habermas, principalmente aquela desenvolvida na década de 1990, não está mais atrelada a projeto explícito de ciência social reconstrutiva. É verdade que ainda há preocupação 
em lidar indiretamente com dados empíricos somados à reconstrução de teorias. No entanto, apenas admitindo nexo mais estreito com a pesquisa social será possível reconectar conceitos teóricos centrais e suas aspirações normativas a conflitos do presente. Isso, conforme tentarei deixar mais claro na próxima seção, não implica prejuízos para a teoria sistematicamente edificada. A relação com a pesquisa empírica não consiste em inviabilizar conceitos teóricos, mas permitir sua renovação mediante o próprio procedimento reconstrutivo.

Esse é precisamente o ponto cego na teoria política habermasiana que Vincent deixou de tematizar porque não considerou em toda sua extensão os potenciais e limites da reconstrução. A teoria política reconstrói com seus conceitos as práticas políticas sobre as quais se debruça na mesma medida em que permite reconstruir a si mesma nesse mesmo procedimento. Trata-se de uma via de mão dupla entre teoria e empiria, que estaria aberta desde sempre para uma teoria cujas categorias necessitam ser testadas socialmente, algo natural, por assim dizer, para teorias políticas reconstrutivas que não deixaram de compreender sua relação com contextos de surgimento e de aplicação a que se destinam. Portanto, o procedimento reconstrutivo pensado em conexão com a pesquisa social é tanto mais necessário quanto mais a teoria política reconstrutiva passa a se afastar de sua gênese empírica explícita. A reconstrução resulta em forçar a teoria mais uma vez a testar seus próprios conceitos e pressupostos em diagnósticos do presente mediados por pesquisas sociais. O que não significa buscar tão somente uma comprovação empírica a posteriori para a teoria erigida, significa que a fundamentação e a constituição da própria teoria ocorrem complementarmente à pesquisa social, encontrando na empiria não um exemplo exterior, mas as condições de sua própria gênese conceitual. 


\section{A gênese social de conceitos políticos e as lutas por reconhecimento}

A ideia da colaboração entre teoria política reconstrutiva e pesquisa social implica divisão equilibrada de tarefa. A preocupação com a gênese social de categorias políticas não deve sujeitar a teoria à pesquisa social e empírica, mas significa ressaltar que o processo reconstrutivo dessas categorias está voltado para fenômenos dinâmicos, multifacetados e muitas vezes ambíguos. Formulado em termos negativos, os conceitos não precisam estar resguardados de uma vez por todas contra casos concretos. Não pressupõe certamente que o conceito político é superior à realidade política empírica, como se fosse a verdade do "caos" e da "inferioridade" do meramente empírico. A teoria política contribui com a própria pesquisa social na medida em que seus conceitos se mostram inscritos nos fenômenos políticos sobre os quais a pesquisa se debruça. A pesquisa social, por sua vez, é parte constitutiva dos conceitos reconstruídos teoricamente. $\mathrm{O}$ efeito constitutivo de uma sobre a outra me parece bastante frutífero quando se trata de produzir diagnósticos de tempo, quase como correção recíproca de ambas as partes. Se, de um lado, o trabalho conjunto de teoria política e pesquisa social evitaria "normativismo" excessivo e abstrato, também permitiria, do outro, atentar contra um positivismo hoje dominante do trabalho de descrição empírica dos processos.

Claro que, do ponto de vista da teoria, tal procedimento reconstrutivo deve permitir uma radical atualização dos conceitos empregados inicialmente. Existem casos em que conceitos são explicitamente inadequados para a compreensão de determinados processos e contextos, mas existem outros casos em que certos conceitos permitem explicações parciais, levando à necessária reconstrução por parte da própria teoria. Isso ocorre quando a teoria política e a pesquisa social estão intimamente vinculadas no estudo 
de conflitos sociais. Conflitos precisam ser investigados de muitos pontos de vista, com diferentes atores e processos em questão, e também com diferentes expectativas, necessidades e interesses em disputa. É mais natural que, em contextos de disputa, seja muito difícil encontrar uma única saída conceitual e normativa de dentro dos próprios processos investigados. Nesses casos, o primeiro fato a considerar é que a teoria política (principalmente a de teor normativo) não deve se preocupar em sempre precisar encontrar para certos males sociais (certas formas de dominação ou de injustiça social) determinados "remédios" normativos, como se seu propósito maior fosse indicar soluções para os problemas diagnosticados. Pressupondo que esse não é o propósito final da teoria política (mas o de contribuir na produção de diagnósticos a respeito dos conflitos sociais do presente), o procedimento de investigação envolvido no andamento da pesquisa poderá mostrar que diferentes saídas estão pre224 sentes (ou que não estão, dependendo do diagnóstico) e que ao teórico cabe analisá-las em toda sua complexidade. Mas quais conceitos políticos poderiam resistir a esse grau de indeterminação prática a que toda pesquisa social está sujeita?

Se a teoria política nos ajuda a refletir sobre disputas normativas, então não é desejável que conceitos sejam utilizados sem fissuras nem torções. Se olhamos para disputas atuais em torno da dominação de gênero, poderemos observar que praticamente todos os conceitos centrais empregados pela teoria política precisou sofrer modificações (muitas vezes bruscas). Liberdade, justiça, autonomia, igualdade, democracia, reconhecimento, poder, cidadania, representação, participação, entre outros, foram conceitos testados tendo em vista o problema da dominação de gênero e seus efeitos sobre as esferas e instituições sociais, culturais, políticas e econômicas. Do ponto de vista da teoria política reconstrutiva, de modo algum a produção de diagnósticos 
de tempo envolvendo gênero falou desfavoravelmente a tais conceitos enquanto tais, pois somente assim contribui em sua renovação e atualização, isto é, para a finalidade maior de compreensão rigorosa e crítica das nossas sociedades atuais. Esse procedimento envolveu reconstrução em campo bastante ampliado do domínio do político, que é institucionalmente transversal e presente nas mais diversas esferas sociais. Por essa razão, a reconstrução exige que se busque a gênese social das gramáticas de luta em modos de vida e de socialização, em experiências cotidianas e como parte fundamental de uma cultura política não unitária e homogênea (Melo, 2015, 2016). ${ }^{5}$

Se olharmos para o conceito de reconhecimento, talvez fique mais clara a relação conceitual com a gênese social. O conceito de reconhecimento acompanhou uma diversidade muito grande de fenômenos políticos atuais (com disputas em torno de gênero, raça, sexualidade, minorias étnicas etc.). Além disso, também sempre foi empregado junto com a ideia de uma luta por reconhecimento que pretendia esclarecer a gramática moral que acompanhava a diversidade de demandas dos movimentos sociais (Taylor, 2000; Honneth, 2003; Fraser, 2001; Thompson, 2006). Contudo, precisamente na medida em que esse conceito deriva de diferentes dimensões das lutas políticas, levanta-se a dificuldade de seu escopo empírico e de seu risco de déficit sociológico (Melo, 2017). Se a virtude teórica do reconhecimento reside em seu ancoramento na práxis política (vinculado sempre ao paradigma da "luta"), por outro lado, é preciso estar ciente do risco de transformar o reconhecimento na gramática de todos os conflitos sociais. Muito

\footnotetext{
${ }^{5}$ No mesmo sentido em que Cefaï (1997) tem empregado o conceito de "cultura política" em seus escritos, sempre ancorando as expectativas normativas nas interações e comunicações cotidianas. $\mathrm{O}$ autor demostra em pesquisas empíricas de que maneira as negociações simbólicas e normativas que produzem cotidianamente as culturas políticas devem ser investigadas segundo "a singularidade e a concretude da experiência democrática" (p. 152).
} 
do emprego equivocado do conceito de reconhecimento derivou, assim, do fato de ter sido utilizado como condição teórica prévia e já bem fundamentada para posterior análise de casos. Mas a ordem precisa ser invertida: se a pesquisa sobre determinado conflito permitir que uma de suas gramáticas normativas seja a do reconhecimento, então é possível passar a uma fundamentação conceitual, mas guardadas as especificidades, ambiguidades e multidimensionalidades do caso.

Por outro lado, o conceito de reconhecimento já vem sendo testado de maneira exitosa em diversas pesquisas empíricas, incluindo no Brasil. ${ }^{6}$ Seu sucesso se deve à capacidade de enriquecer diagnósticos críticos do presente e, em particular, a esclarecer processos de políticas de reconhecimento. Mas também aprendemos com seus limites explicativos, ensinando-nos que o reconhecimento precisa ser repensado com análises sociais mais porosas a realidades históricas e espaciais em constante mudança. Portanto, todo o trabalho de reconstrução de perspectivas normativas enraizadas nos processos sociais e políticos analisados teria muito a se beneficiar da colaboração com pesquisas interdisciplinares, mesmo que isso implicasse custos às pretensões sistemáticas da teoria normativa defendida.

Ora, a gramática do reconhecimento tem de emergir do domínio do social, isso é, precisa produzir expectativa normativa (por exemplo, tendo em vista prover a proteção contra prejuízos advindos do desrespeito, exclusão e humilhação) que seja interna aos próprios conflitos. Em outras

\footnotetext{
${ }^{6}$ São muitas as referências atualmente sobre pesquisas empíricas e o conceito de reconhecimento. Gostaria de exemplificar aqui aquelas em que o conceito não é simplesmente aplicado às realidades sociais e históricas concretas, mas apresenta possibilidade de ser reconstruído a partir de cada caso. Uma coletânea com diversos trabalhos se encontra em O'Neill e Smith (2012). Sobre reconhecimento nas relações do mercado de trabalho, cf. Renault (2017). Interessante insight tem sido levado a cabo na pesquisa sobre a ocupação das escolas públicas pelos secundaristas em Medeiros e Januário (2017).
} 
palavras, a experiência da falta de reconhecimento ou do reconhecimento denegado e a motivação moral que produz não podem ser externas às interações sociais. Assim, a teoria do reconhecimento garantiria, de maneira a princípio bem fundamentada, a desejada imanência social de suas categorias crítico-normativas do ponto de vista das exigências reconstrutivas da teoria. Mas basta que outros e novos contextos sociais sejam avaliados teoricamente para que possamos colocar em suspenso a validade normativa do conceito. Se a tese forte da teoria do reconhecimento consiste, de um lado, em mostrar que certas experiências negativas vividas por certos indivíduos e grupos seriam capazes de desencadear lutas moralmente motivadas, de outro, isso não significa ter de aceitar o reconhecimento como gramática totalizante e homogênea dos conflitos sociais como um todo. A pesquisa social poderia, assim, avaliar a pertinência empírica do conceito, não apenas tendo em vista saber se é possível que o reconhecimento esteja de fato presente como parte de uma disputa social investigada, mas também considerando se não se manifesta de forma modificada e ambígua, além de concorrer com outras possíveis gramáticas num mesmo processo. Tal reacomplamento mais estreito com a pesquisa social certamente teria impacto decisivo no estágio atual da teoria do reconhecimento, que na minha perspectiva ainda apresenta potencial muito importante para a análise de formas de conflito nas sociedades do presente. $^{7}$

Estou sugerindo, portanto, que possamos sem custo recusar a intenção sistemática do reconhecimento como

\footnotetext{
7 É preciso considerar também a complexidade do tema da pesquisa social para a teoria política (cf. Voirol, 2012). Existiriam diferentes maneiras de produzir diagnóstico, não conduzidas simplesmente por metodologias tradicionalmente empregadas e, muitas vezes, de viés positivista. Ela precisa ser aberta em relação à organização disciplinar, cruzar aspectos de uma investigação qualitativa com dados quantitativos, lançar mão de entrevistas e grupos focais, contar com observação participante e confrontar tentativas de diagnóstico de tempo. Mas sua vantagem é se servir da cultura, da política, da psicologia e da economia sem previamente determiná-las pela pretensão normativa da teoria.
} 
categoria política explicativa. Nesse sentido, abrimos margem para utilização bem mais limitada e modesta dos conceitos da teoria política, no sentido de testar seu potenciais explicativos e críticos fundados em determinados casos empíricos bem diagnosticados. Insisto que não seria frutífero subsumir a completude das demandas políticas a uma categoria única e não me refiro, evidentemente, apenas ao reconhecimento. A seleção conceitual depende do próprio contexto e da natureza dos conflitos sobre os quais nos debruçamos. A pesquisa social pode ajudar a mostrar que o reconhecimento é um dos pontos de vista normativos passíveis de ser reconstruídos por uma teoria política, mas que assume posição reconstrutiva derivada, isto é, nunca na qualidade de condição original que antecede o conflito, mas sempre aspiração normativa entre outras possíveis. Dessa forma, teoria política e pesquisa social contribuiriam conjuntamente para compreensão adequada dos desafios políticos das atuais sociedades democráticas.

\section{Rúrion Melo}

é professor do Departamento de Ciência Política da Universidade de São Paulo e pesquisador do Centro Brasileiro de Análise e Planejamento (Cebrap).

\section{Bibliografia}

BERNSTEIN, R. 1976. The restructuring of social and political theory.

Pennsylvania: University of Pennsylvania Press.

CEFAÏ, D. 1997. Outro enfoque de la cultura política: repertorios de identidade y marcos de interacción, formatos narrativos de los acontecimentos públicos, regímenes de negociación y arreglos sindicales. Foro Internacional, n. 37, p. 150-162.

FRASER, N. 2001. Da redistribuição ao reconhecimento? Dilemas da justiça na era pós-socialista. Tradução de Julio Assis Simões. In: SOUZA, J. (org.). Democracia hoje: novos desafios para a teoria democrática contemporânea. Brasília: UnB, pp. 245-282. 
HABERMAS, J. 1994. Faktizität und Geltung. Frankfurt am Main: Suhrkamp. 2008. Hat die Demokratie noch eine epistemische Dimension? Empirische Forschung und normative Theorie. In: HABERMAS, J. Ach, Europa. Frankfurt am Main: Suhrkamp, pp. 138-191. 2013. Teoria e práxis. Tradução de Rúrion Melo. São Paulo: Unesp. 2016. Para a reconstrução do materialismo histórico. Tradução de Rúrion Melo. São Paulo: Unesp.

HONNETH, A. 2003. Luta por reconhecimento: a gramática moral dos conflitos sociais. Tradução de Luiz Repa. São Paulo: Editora 34.

HORKHEIMER, M. 2009. Die gegenwärtige Lage der Sozialphilosophie und die Aufgaben eines Instituts für Sozialforschung [1931]. In: . Gesammelte Schriften. Bd. 3. Frankfurt am Main: Fischer, pp. 20-35.

JAY, M. 2008. A imaginação dialética: história da escola de Frankfurt e do Instituto de Pesquisas Sociais, 1923-1950. Tradução de Vera Ribeiro. Rio de Janeiro: Contraponto.

MCCARTHY, T. 1981. The critical theory of Jürgen Habermas. Cambridge: MIT.

MEDEIROS, J; JANUÁRIO, A. 2017. Desrespeito, indignação ou injustiça: o que motivou os secundaristas paulistas a ocuparem suas escolas? Trabalho apresentado no XVIII Congresso Brasileiro de Sociologia, Brasília, 26 a 29 de julho. Disponível em: <http:/ /sbs2017.com.br/ anais/resumos/PDF-eposter-trab-aceito-0897-1.pdf>. Acesso em: 10 nov. 2017.

MELO, R. 2015. Repensando a esfera pública: esboço de uma teoria crítica da democracia. Lua Nova, n. 94, pp. 11-39. 2016. O "paradoxo" da democracia radical: crise, protestos e perda de legitimação. DoisPontos, v. 13, n. 2., pp. 71-82. . 2017. Repensando o déficit sociológico da teoria crítica: de Honneth a Horkheimer. Cadernos de Filosofia Alemã: Crítica e Modernidade, 22, v. 2, pp. 63-76.

MELO, R.; SILVA, F. G. 2012. Crítica e reconstrução em Direito $e$ democracia. In: NOBRE, M.; REPA, L. (orgs.). Habermas e a reconstrução. Campinas: Papirus, pp. 135-168.

NOBRE, M.; REPA, L. 2012. Reconstruindo Habermas: etapas e sentido de um percurso. In: NOBRE, M.; REPA, L. (orgs.). Habermas e a reconstrução. Campinas: Papirus, pp. 13-42.

O’NEILL, S.; SMITH, N. H. (orgs.) 2012. Recognition theory as social research: investigating the dynamics of social conflict. New York: Palgrave Macmillan. 
RENAULT, E. 2017. L'expérience de la justice. Paris: La Découverte.

TAYLOR, C. 2000. A política do reconhecimento. In: TAYLOR, C.

Argumentos filosóficos. Tradução de Adail Ubirajara Sobral. São Paulo:

Loyola, pp. 241-274.

THOMPSON, S. 2006. The political theory of recognition: a critical introduction. Cambridge: Polity.

VINCENT, A. 2004. The nature of political theory. New York: Oxford University.

VOIROL, O. 2012. Teoria crítica e pesquisa social: da dialética à reconstrução. Novos Estudos - Cebrap, n. 93, pp. 81-99. 


\section{)}

\section{TEORIA POLÍTICA E PESQUISA SOCIAL}

\section{RÚRION MELO}

Resumo: Este artigo procura pensar a relação complementar entre teoria política e pesquisa social. Para tanto, procura-se primeiramente especificar potenciais e limites do método reconstrutivo na teoria política e de que maneira poderia, de um lado, superar a dicotomia entre teorias empíricas e normativas da política e, de outro lado, apontar para uma constituição aberta dos conceitos políticos baseada em seus contextos históricos e sociais. Depois, ressalta-se a gênese social dos conceitos por uma análise da teoria do reconhecimento e de pesquisas sociais empíricas que têm ajudado na renovação e atualização desses fundamentos.

Palavras-chave: Teoria Política; Pesquisa Social; Reconstrução; Reconhecimento.

\section{POLITICAL THEORY AND SOCIAL RESEARCH}

Abstract: In this article, we aimed at thinking the complementary relation between political theory and social research. To achieve our objective, firstly we specified the reconstructive method's potential and limits on political theory and how could it overcome the empirical and normative political theories dichotomy, and, on the other side, we indicated an open constitution of political concepts based on historical and social contexts. Later, we highlighted these concepts social genesis by analyzing the theory of recognition and empirical social researches that have helped the renewal and upgrade of these foundations.

Keywords: Political Theory; Social Research; Reconstruction; Recognition.

Recebido: 11/07/2017

Aprovado: 07/11/2017 